\title{
Low-temperature lithium diffusion in simulated high-level boroaluminosilicate nuclear waste glasses
}

\section{Authors:}

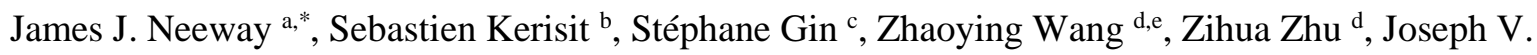
Ryan $^{\text {a }}$

\author{
Affiliation: \\ ${ }^{a}$ Energy and Environment Directorate, Pacific Northwest National Laboratory, Richland, WA 99352, \\ USA \\ ${ }^{b}$ Fundamental and Computational Sciences Directorate, Pacific Northwest National Laboratory, \\ Richland, WA 99352, USA \\ ${ }^{c}$ CEA Marcoule DTCD SECM, LCLT, F-30207 Bagnols-sur-Cèze, France \\ ${ }^{d}$ Environmental Molecular Sciences Laboratory, Pacific Northwest National Laboratory, Richland, WA \\ 99352, USA \\ ${ }^{e}$ Institute of Chemistry, Chinese Academic of Science, Beijing, China, 100190

\section{* Corresponding Author:} \\ James.Neeway@pnnl.gov
}

\begin{abstract}
Ion exchange is recognized as an integral, if underrepresented, mechanism influencing glass corrosion. However, due to the formation of various alteration layers in the presence of water during the corrosion process, it is difficult to conclusively deconvolute the mechanisms of ion exchange from other simultaneously occurring processes. In this work, an inert non-aqueous solution was used as an alkali source material to isolate ion exchange and study the solid-state diffusion of lithium. Specifically, the experiments involved contacting simulated nuclear waste glass coupons, the 6-oxide CJ-6 and the 26oxide SON68, with a non-aqueous solution of ${ }^{6} \mathrm{LiCl}$ dissolved in dimethyl sulfoxide at $90{ }^{\circ} \mathrm{C}$ for various time periods. The depth profiles of major elements in the glass coupons were measured using time-offlight secondary ion mass spectrometry (ToF-SIMS). Lithium interdiffusion coefficients, $D_{L i}$, were then calculated based on the measured depth profiles. The results indicate that the penetration of ${ }^{6} \mathrm{Li}$ is faster in the simplified CJ-6 $\left(D_{6 L i} \approx 4.0-8.0 \times 10^{-21} \mathrm{~m}^{2} / \mathrm{s}\right)$ compared to the more complex SON68 $\left(D_{6 L i} \approx 2.0\right.$ -
\end{abstract}


$4.0 \times 10^{-21} \mathrm{~m}^{2} / \mathrm{s}$ ). These values are roughly an order of magnitude greater than measured water diffusion in glasses at similar temperatures. Additionally, sodium ions present in the glass were observed to participate in ion exchange reactions with lithium from solution. Implications of the diffusion coefficients obtained in the absence of alteration layers to the long-term performance of nuclear waste glasses in a geological repository system are also discussed.

\section{Introduction}

Boroaluminosilicate glasses are employed in a wide range of applications including fiberglass (Varshneya, 1994), substrate glasses in active matrix liquid crystal displays (Ellison and Cornejo, 2010; Kato et al., 2001), and high-level nuclear waste glasses (Jantzen et al., 2010; Vienna, 2010). In the context of nuclear waste glasses, understanding the corrosion behavior of borosilicate glasses is intimately tied to the ability to safely store the material in a deep geological repository (Gin et al., 2013a). An important mechanism involved in the alteration of nuclear waste glasses is ion exchange. Although ion exchange was initially considered not to control the long-term release of radionuclides (Vernaz and Dussossoy, 1992), more researchers have provided evidence of its influence on the long-term glass corrosion rate in specific conditions (Frugier et al., 2008; Grambow and Müller, 2001; McGrail et al., 2001). However, due to the slow reaction kinetics of nuclear waste at long time periods, it is difficult to isolate the rate of ion exchange from the other potential mechanisms controlling the long-term dissolution rate. This complexity highlights the need for a better understanding of ion exchange.

To understand the role of ion exchange during the corrosion of glass, we will give a brief review of the corrosion processes that occur when a pristine glass sample is placed in deionized water. Deionized water equilibrated with atmospheric $\mathrm{CO}_{2}$ is slightly acidic, therefore, at short time periods ion exchange is the preferential mechanism of the water-glass reaction. The overall chemical reaction describing the exchange of a cation, $\mathrm{M}^{+}$, with a water species is written as:

$(\equiv \mathrm{Si}-\mathrm{O}-\mathrm{M})_{\text {glass }}+\mathrm{H}_{2} \mathrm{O} \rightarrow(\equiv \mathrm{Si}-\mathrm{OH})_{\text {glass }}+\mathrm{M}^{+}+\mathrm{OH}^{-}$ 
This reaction leads to an increase in solution $\mathrm{pH}$. It should be noted that the actual species of water (i.e. molecular water, the hydronium ion, or a proton) that participates in this reaction is unknown. As the $\mathrm{pH}$ increases, hydrolysis of the silicate network then occurs preferentially to ion exchange. Throughout this time, ion exchange and hydrolysis are occurring simultaneously but the rates of each reaction differ across the $\mathrm{pH}$ range. As the concentration of dissolved components increases, a hydrated, silica-rich, cationdepleted, thermodynamically unstable phase, commonly referred to as the gel, is formed. This hydrated surface layer is composed primarily of sparingly soluble glass components (i.e. $\mathrm{Al}, \mathrm{Fe}$, and $\mathrm{Si}$ ) that form either by the glass network restructuring after leaching or recondensation (i.e. the back reaction in the dissolution step). During this time, the matrix dissolution rate becomes dependent on the solution saturation state (concentration of elements in solution) and the overall glass dissolution rate slows. The slowing of the dissolution rate has been attributed to a combination of the effect of increasing $\mathrm{H}_{4} \mathrm{SiO}_{4}(\mathrm{aq})$, as described by transition-state theory, and the formation of a diffusion-limiting surface layer (Van Iseghem et al., 2006). Eventually, the glass dissolution rate slows to a constant "final" or "residual" rate. It should be noted that at high temperature or in hyperalkaline conditions, the glass dissolution rate can increase and approach values similar to the initial rate. This excursion from the final rate often coincides with the appearance of zeolitic alteration phases (Ebert et al., 2012; Fournier et al., 2014; Ribet and Gin, 2004; Strachan and Neeway, 2014).

Although ion exchange has not received the level of attention that network hydrolysis and matrix dissolution have, it has been the focus of some studies in nuclear waste glasses (Icenhower et al., 2002; McGrail et al., 2003; McGrail et al., 2001; Ojovan et al., 2006; Pierce et al., 2005). With the exception of Ojovan et al. (2006), who modelled release rates of radionuclides using diffusion controlled ion exchange (i.e. time dependent), the authors used experimental data and determined that the ion exchange reaction persisted throughout the glass dissolution process and that the rate of ion exchange was constant. It has also been concluded that the importance of the ion exchange process may be especially relevant at low temperature and in solution near saturation with respect to $\mathrm{SiO}_{2}(\mathrm{am})$ where the hydrolysis reaction is 
suppressed(McGrail et al., 2001; Ojovan et al., 2006). Through the entire corrosion process, the ion exchange process is expected to occur even though it is not controlling the overall dissolution rate. Because ion exchange involving a water species will result in the formation of alteration layers, in this paper we attempt to isolate the ion exchange mechanism from the other mechanisms that occur concurrently during the corrosion process by exchanging the alkali ion, $\mathrm{Li}$, for other alkali ions in the glass network. By doing this, we can quantify ion exchange diffusion coefficients which can then be used to understand the effect of ion exchange in the presence of the alteration layers created during the aqueous corrosion of nuclear waste glasses.

Thus far, we have focused on the interdiffusion of water species with alkali ions. However, alkali-alkali interdiffusion in borosilicate glasses is also possible (El-Shamy and Pantano, 1977). The process has been exploited for industrial applications such as high-strength ion exchange glasses used as glass covers for personal electronic devices (Guo et al., 2014; Smedskjaer et al., 2011; Varshneya, 2010; Wu et al., 2012). To understand alkali diffusion, it is important to understand the structural role of the alkalis in the glass. Alkali ion addition to $\mathrm{SiO}_{2}$ depolymerizes the silicate network and creates non-bridging oxygens (NBO). Because of this, alkali ions are known as network modifiers. When $\mathrm{Al}^{3+}$ and $\mathrm{B}^{3+}$ are added to the silicate network, the alkali ions tend to act as charge-balancing species for tetrahedral $\mathrm{AlO}_{4 / 2}^{-}$and $\mathrm{BO}_{4 / 2}^{-}$units. It has been previously demonstrated that the diffusivity of alkali ions may change whether they are charge compensating $\mathrm{Al}^{3+}, \mathrm{B}^{3+}$, or located on NBO sites (Smedskjaer et al., 2011). To our knowledge, the alkalialkali ion exchange reaction has not been studied for glasses relevant to the immobilization of high-level nuclear waste.

One way to investigate the ion exchange rate is through isotope tracing. This powerful technique has previously been used to understand glass corrosion processes including the role of water dissociation in ion exchange (McGrail et al., 2001), the penetration of water into the glass structure (Cailleteau et al., 2008; Rébiscoul et al., 2007), and the extent of solution involvement in gel formation (Jollivet et al., 2008; Valle et al., 2010). The method has also been used to study the diffusion of alkali elements, mostly 
used in glass-strengthening, but these are often conducted at temperatures at or near the glass fictive temperature, $T_{g}$ (Smedskjaer et al., 2011; Wu et al., 2012) (i.e. much higher than the temperatures expected in a geological repository), and the technique relies on introducing the glass in a molten salt bath where alkali ions of the glass exchange with alkali ions in the bath.

In this set of experiments, the diffusion of Li is studied in two simulated high-level waste glasses, SON68 and CJ-6, through the use of lithium isotopes. Lithium is also often used as a glass tracer in glass dissolution experiments (Ferrand et al., 2006; Neeway et al., 2011). Lithium, the lightest and smallest of the alkali metals, may be added to the glass batch in order to decrease the melting point, viscosity, and thermal expansion of the glass. Understanding the solid-state diffusion of $\mathrm{Li}$ in glassy materials would help with bounding this diffusion-controlled reaction in modelling of the long-term dissolution of nuclear waste glasses as it may be the fastest possible diffusing species due to its small size. It is also of use in the future development of ion-strengthened glasses, which often contain lithium that exchanges with larger alkali cations at the surface. The low-temperature diffusivity of alkali ions are of critical importance to the long-term persistence of chemical strengthening in technical glass products.

\section{Experimental}

\subsection{Glass Fabrication and Preparation}

Because of its nearly identical composition to the radioactive waste glass, R7T7, produced at the Areva reprocessing site in La Hague, France, the SON68 glass composition has been the subject of many studies (Advocat et al., 2001; Chomat et al., 2012; Gin et al., 2013a; Gin et al., 2013b; Gong et al., 1998; Guittonneau et al., 2011; Jollivet et al., 2012; Neeway et al., 2011; Neeway et al., 2012), and references therein. The CJ-6 glass composition is a simplified version of SON68 that was initially designed to investigate the role of the major elements in SON68 (Gin et al., 2012; Jégou, 1998). The molar ratios of the 8-oxide CJ-6 glass are equivalent to those found in SON68 (Table 1). The molar ratios Si/B, Si/Na, and $\mathrm{Si} / \mathrm{Al}$ are $1.88,2.40$, and 7.87 , respectively, for both glasses. The composition of CJ-6 is nearly 
equivalent to the International Simple Glass (ISG) that is currently being investigated as part of an international effort to reach a consensus on the mechanisms controlling the long-term glass dissolution rate (Gin et al., 2013a). The major difference between ISG and CJ-6 is that CJ-6 contains $\mathrm{Li}_{2} \mathrm{O}$ and $\mathrm{Ce}_{2} \mathrm{O}_{3}$, which is used as a surrogate for all the rare earth elements.

The SON68 glass was made by batching carbonates and oxides of the various metals, melting in a furnace at $1250{ }^{\circ} \mathrm{C}$ for one hour, and quenching on a stainless steel plate. This glass was then crushed and remelted for one hour to ensure a homogeneous solid. The second melt was poured into molds to produce rectangular bars. Coupons were cut using a diamond wafering blade for final dimensions of approximately $1.5 \times 1.5 \times 0.2 \mathrm{~cm}$. All sides of the coupons were polished to $3 \mu \mathrm{m}$ with the use of a polycrystalline diamond suspension. The CJ-6 coupons were supplied by the Commissariat à l'énergie atomique et aux énergies alternatives (CEA) (Jégou, 1998).

\subsection{Glass Diffusion Experiments}

Solutions were made by dissolving enriched ${ }^{6} \mathrm{LiCl}$ (95\%, Cambridge Isotope Laboratories, Inc.) in dimethyl sulfoxide (DMSO, Sigma) to obtain a final concentration of $4.5 \mathrm{~g} \mathrm{LiCl} / \mathrm{kg} \mathrm{DMSO}$. DMSO has been demonstrated to have a decomposition rate of $<0.001 \% /$ day when held at $90{ }^{\circ} \mathrm{C}$ in a non-reactive container (Traynelis and Hergenrother, 1964).

A schematic representation of the experimental system based on the setup used in the Vapor Hydration Test (VHT) (Jiřička et al., 2001) is given in Figure 1. We slightly modified the VHT system by inserting a fused silica crucible as an interior liner to prevent the DMSO from contacting the stainless steel. The polished glass coupons, which were hung with the use of a platinum wire from a horizontal fused silica rod, were completely submerged in the ${ }^{6} \mathrm{Li} / \mathrm{DMSO}$ solution. The interior liner was closed with a quartz lid and sealed with Teflon tape to minimize evaporation of DMSO from the container, which may react with the stainless steel. The entire unit was placed in a stainless steel vessel and closed.

The system was set in an oven at $90{ }^{\circ} \mathrm{C}$ and coupons were sampled at 10,30 , and 89 days. When the coupon was removed from each vessel, it was rinsed with clean DMSO, water, then ethanol, and then 
dried in an oven at $90{ }^{\circ} \mathrm{C}$ for several minutes. The coupon surfaces were analyzed with time-of-flight secondary ion mass spectrometry (ToF-SIMS) depth profiling. A ToF-SIMS spectrometer (TOF.SIMS5, IONTOF GmbH, Münster, Germany) was used to perform depth profiling experiments. Dual beam depth profiling strategy was used. A $1.0 \mathrm{keV} \mathrm{O}_{2}{ }^{+}$beam (for $<0.5 \mu \mathrm{m}$ depth profiling) or a $20 \mathrm{keV} \mathrm{Ar}_{\mathrm{n}}{ }^{+}$beam (for $>0.5 \mu \mathrm{m}$ depth profiling) was used as a sputter beam, which was scanned on a $300 \times 300 \mu \mathrm{m}^{2}$ (for $\mathrm{O}_{2}{ }^{+}$beam) area or a $200 \times 200 \mu \mathrm{m}^{2}$ (for $\mathrm{Ar}_{\mathrm{n}}{ }^{+}$beam) area. The use of an $\mathrm{Ar}_{\mathrm{n}}{ }^{+}$beam for depth profiles on insulating materials has been the subject of a recent study (Wang et al., 2014). A $25.0 \mathrm{keV} \mathrm{Bi}^{+}$beam was used as an analysis beam, which was scanned on a $100 \times 100 \mu \mathrm{m}^{2}$ area at the center of the sputter crater. The relatively higher Na signal noise is due to a Poisson correction needed as a result of the dead time during signal counting. After the SIMS measurement, a stylus profilometer was used to measure the crater depth, and a constant sputter rate is assumed. We note that the data obtained near the surface, which are given in the results section, have some inherent uncertainties due to surface contamination, surface roughness, and the time to obtain a stable sputtering surface.

\subsection{Diffusion Mathematics}

In this section, we give a detailed description of the mathematical framework used to interpret the depth profiles obtained experimentally. Specifically, two models are used to fit the depth profiles: an isolated diffusion model and an interdiffusion model. As will be demonstrated in the Results section, ${ }^{6} \mathrm{Li}^{+}$in the non-aqueous solution is found to exchange only with other alkali ions (i.e. $\mathrm{Li}^{+}$and $\mathrm{Na}^{+}$) in the glass; therefore, only mass conservation equations are considered in the two models. Many of the ideas given here are presented in greater detail in an article by Hellmann (1997) and the references therein.

\subsubsection{Isolated diffusion}

In this model, the diffusion of a given species is independent of that of any other species and is described using Fick's $2^{\text {nd }}$ law:

$$
\frac{\partial C}{\partial t}=\frac{\partial}{\partial x}\left(D \frac{\partial C}{\partial x}\right)
$$


where $C$ is the concentration, $t$ is time, $x$ is the depth, and $D$ is the diffusion coefficient. If the diffusion coefficient is a constant with time and depth, the concentration, $C(x)$, of a given species at depth $x$ can be calculated relative to its concentration at depth $0, \mathrm{C}_{0}$, using (Crank, 1975)

$$
C(x)=C_{0} \operatorname{erfc} \frac{x}{2 \sqrt{(D t)}}
$$

However, the diffusion coefficients of the two exchanging species have to be identical to maintain mass balance. Therefore, the diffusion of two exchanging species with this model results in profiles where the inward and outward diffusing species are exactly anti-correlated. This approach is often used when attempting to model observed diffusion profiles of weathered nuclear waste glasses (Chave et al., 2007).

\subsubsection{Interdiffusion}

In the interdiffusion model, it is assumed that the inward and outward diffusing species are not independent of one other. The diffusion behavior of such a system can be described using a single interdiffusion coefficient, $\tilde{D}$, where $\tilde{D}$ varies as a function of the concentration of the diffusing species.

In other words, $\tilde{D}$ varies with time and depth as the concentrations evolve with time. For the case where the inward diffusing species, $A$, and outward diffusing species, $B$, have the same charge and the activity coefficients are assumed to be unity, $\tilde{D}$ is defined through the following expression (Doremus, 1975; Hellmann, 1997):

$$
\tilde{D}=\frac{D_{A} D_{B}}{C_{B} D_{B}+\left(1-C_{B}\right) D_{A}}
$$

where $D_{A}$ and $D_{B}$ are the individual diffusion coefficients and $C_{B}$ is the bulk normalized concentration of $B$. Equation 3 is usually sufficient to fit diffusion profiles of two species, especially the sigmoidal profiles often observed experimentally. However, to have a more complete model, a structural term, $\alpha$, may be introduced. Mathematically, this term is used to increase the diffusion of species near the solution/glass interface without changing $D_{A}$ and $D_{B}$. The physical meaning of this term may be explained in terms of a 
change in the diffusion coefficient with depth as a result of the exchange of a larger cation for a smaller cation that then facilitates diffusion of the smaller cation in the region depleted in the larger cation. The treatment of $\alpha$ is given in the following equation (Lanford, 1979):

$$
\tilde{D}_{\alpha}=\left(1+\alpha C_{A}\right) \tilde{D}
$$

It should be noted that when $\alpha=0$, (i.e. no structural term), $\tilde{D}_{\alpha}$ is equal to $\tilde{D}$.

The use of an interdiffusion model is a strategy often employed when modeling $\mathrm{H}^{+}$exchange for cations in a glassy material. The method was first proposed by Doremus (1975), modified by Lanford (1979) and is still utilized to explain diffusion behavior related to nuclear waste glass dissolution (Chave et al., 2007; Ferrand et al., 2006; Gin et al., 2013b; Ojovan et al., 2006; Rébiscoul et al., 2007; Valle et al., 2010). However, because these previous studies dealt with ion exchange during glass corrosion, they necessitated the incorporation of a moving boundary in the diffusion model. In the experiments performed in this study, we have eliminated the moving boundary (i.e. prevented surface corrosion), allowing for the use of a simplified model.

In the experiments carried out in this work, three species are involved in the ion exchange process, namely, ${ }^{6} \mathrm{Li}^{+},{ }^{7} \mathrm{Li}^{+}$and $\mathrm{Na}^{+}$. Therefore, the interdiffusion model was slightly reformulated to treat the diffusion of the three species consistently. It is assumed that the diffusion coefficients of the three species are all dependent on the $\mathrm{Na}$ concentration, whereby diffusion near the glass surface, where the $\mathrm{Na}$ concentration is low due to Na depletion, is faster than diffusion in the bulk of the glass, where the $\mathrm{Na}$ concentration is higher. It is also assumed that ${ }^{6} \mathrm{Li}^{+}$and ${ }^{7} \mathrm{Li}^{+}$have identical diffusion coefficients. Therefore, one expression is written to calculate $\tilde{D}$ for each of $\mathrm{Li}$ and Na:

$$
\widetilde{D}_{\mathrm{Li}}=\left(1+\alpha\left(1-C_{\mathrm{Na}}\right)\right) \frac{D_{\mathrm{Li}}^{\mathrm{s}} D_{\mathrm{Li}}^{\mathrm{b}}}{C_{\mathrm{Na}} D_{\mathrm{Li}}^{\mathrm{s}}+\left(1-C_{\mathrm{Na}}\right) D_{\mathrm{Li}}^{\mathrm{b}}}
$$




$$
\tilde{D}_{\mathrm{Na}}=\frac{D_{\mathrm{Na}}^{\mathrm{s}} D_{\mathrm{Na}}^{\mathrm{b}}}{C_{\mathrm{Na}} D_{\mathrm{Na}}^{\mathrm{s}}+\left(1-C_{\mathrm{Na}}\right) D_{\mathrm{Na}}^{\mathrm{b}}}
$$

where $D_{i}^{\mathrm{s}}$ and $D_{i}^{\mathrm{b}}$ are the surface and bulk diffusion coefficient of species $i$, respectively. Note that a structural term is only used for the smaller cation, i.e. Li.

A final note on modeling assumptions is that we assume charge balance is maintained in the glass, the diffusion coefficients are constant with time, and that an infinite source of ${ }^{6} \mathrm{Li}$ is present in solution.

\subsubsection{Computational procedure}

Fick's $2^{\text {nd }}$ law was solved on a one-dimensional grid using the Crank-Nicolson method, a finite difference method that uses second-order central difference in space and trapezoidal rule in time. The grid point spacing was set to $1 \mathrm{~nm}$ and the integration time step to $10 \mathrm{~s}$. The method used 1500 grid points to simulate the glass surface and the calculations were run for up to 777600 steps to simulate diffusion up to 90 days. Initial conditions $(t=0)$ were as follows: $C_{7} \mathrm{Li}=C_{\mathrm{Na}}=0$ and $C_{6} \mathrm{Li}=1$ at $x=0$, and $C_{{ }_{6} \mathrm{Li}}=0$ and $C_{7} \mathrm{Li}=C_{\mathrm{Na}}=1$ at $x>0$. Neumann boundary conditions were applied at both boundaries. The parameters $D_{\mathrm{Li}}^{\mathrm{s}}, D_{\mathrm{Li}}^{\mathrm{b}}, D_{\mathrm{Na}}^{\mathrm{s}}, D_{\mathrm{Na}}^{\mathrm{b}}$, and $\alpha$ were varied to optimize the agreement between calculated and experimental depth profiles.

\section{Results}

\subsection{Diffusion profiles}

Though the focus of this study is on the exchange of alkalis, we examined the ToF-SIMS profiles of all major elements to see if the intensity of the element changed as a function of depth. A change in the intensity would most likely be from water altering the glass surface. Water may be introduced into the system through using DMSO and ${ }^{6} \mathrm{LiCl}$ that contain residual water or water that may be adsorbed on the glass surface as a result of the polishing process. The profiles of $\mathrm{H},{ }^{11} \mathrm{~B},{ }^{27} \mathrm{Al},{ }^{28} \mathrm{Si},{ }^{32} \mathrm{~S},{ }^{40} \mathrm{Ca}$, and ${ }^{140} \mathrm{Ce}$ for CJ-6 sample exposed to the LiCl/DMSO solution for 89 days are given in Figure 2. The H intensity 
comes from measurement using an $\mathrm{O}_{2}{ }^{+}$sputter beam, the $\mathrm{S}$ intensity comes from measurements using a $\mathrm{Cs}^{+}$sputter beam, while the other elements were obtained from an $\mathrm{Ar}_{n}{ }^{+}$sputter beam. It can be seen that the relative intensities for each elemental isotope of the major elements are constant across the majority of the sampled cross section. The profiles do, however, exhibit an enrichment of $\mathrm{H}$ for the first $\sim 15 \mathrm{~nm}$. The enrichment in $\mathrm{H}$ also corresponds with a slight decrease in ${ }^{40} \mathrm{Ca}$ and ${ }^{27} \mathrm{Al}$ intensity in the same depth. Due to inherent polishing defects including roughness as well as charging at the glass surface, the significance of these profiles remains unclear. It can, however, be stated that the intensities of all these measured elements remain constant after the first $15 \mathrm{~nm}$. This depth can be contrasted to the depths of the alkali elements for the same sample that measure between 500 and $600 \mathrm{~nm}$ (see Figure 3b).

\subsection{Alkali Profiles}

Since the profiles of the non-alkali oxides were constant with depth, it is expected that the total alkali content in the glass should be constant with depth (i.e. one ${ }^{6} \mathrm{Li}^{+}$ion would exchange with one ${ }^{7} \mathrm{Li}^{+}$ion or one $\mathrm{Na}^{+}$ion). To demonstrate the conservation of alkali ions, we show the total alkali content normalized to ${ }^{27} \mathrm{Al}$ in Figure 3 for the CJ-6 glass. This figure shows that the total alkali content remains mostly constant across the depth of interest with only a slight depletion in alkali ions near the surface. As mentioned in the previous section, other factors could account for this surface result. Whatever the cause, we have determined that the surface depletion is easily corrected for in the modelling. The same trend is also observed for SON68.

Though the sum of the alkali profiles remains constant, the individual profiles of ${ }^{6} \mathrm{Li},{ }^{7} \mathrm{Li}$, and $\mathrm{Na}$ differ. For ${ }^{6} \mathrm{Li}$, the amount is high near the solution/glass interface and decreases as the profile approaches the pristine glass while ${ }^{7} \mathrm{Li}$ and $\mathrm{Na}$ profiles show depletion at the surface compared with the pristine glass. This observation, shown in Figure 3b, is due to the exchange of the inward-diffusing species, ${ }^{6} \mathrm{Li}$, with the outward-diffusing species. The profiles of ${ }^{6} \mathrm{Li}$ and ${ }^{7} \mathrm{Li}$ seem to have very similar anti-correlated sigmoidal shapes while the Na profile shows a slightly larger depletion depth and, instead of a sigmoidal profile, a somewhat linear shape. The treatment of the two different shapes will be discussed further in the 
modeling section. It should be noted that the relative intensity for the outward-diffusing species does not go to zero at the solution/glass interface suggesting that not all of the alkali ions initially in the glass are available for exchange. Thus a portion of the alkali ions can be considered non-exchangeable.

\subsubsection{Isolated diffusion}

Initially, the Li profiles were fit using an isolated diffusion model (Equation 2). The concentration of the inward diffusing species is defined as one at the surface and zero in the pristine glass. It is evident from

Figure 4 that using this model gives a good estimation of the ${ }^{6} \mathrm{Li}$ maximum penetration depths using $D$ values of $1.0 \times 10^{-20} \mathrm{~m}^{2} / \mathrm{s}$ for CJ-6 and $5.5 \times 10^{-21} \mathrm{~m}^{2} / \mathrm{s}$ for SON68. The same diffusion coefficients also give a relatively good estimation of the depletion depths for ${ }^{7} \mathrm{Li}$ (data not shown). However, this model fails to reproduce the shape of the profiles, especially at longer time periods. The model lacks both the sigmoidal behavior and the apparent faster diffusion of ${ }^{6} \mathrm{Li}$ near the surface. To account for these behaviors, the profiles were then modeled using the interdiffusion method as described in the next section.

\subsubsection{Interdiffusion}

Experimental profiles were also modeled using the interdiffusion model defined by Equations 5 and 6 . The results of these fits for ${ }^{6} \mathrm{Li}$ are given in Figure 5a and b for CJ-6 and SON68, respectively. The model fits the data well for the CJ-6 samples and the long-term SON68 data. However, the short-term data for SON68 overestimates the extent of ${ }^{6} \mathrm{Li}$ penetration near the surface even when the estimated depth of

penetration is reproduced within reason. The data was fit using values for $D_{\mathrm{Li}}^{\mathrm{b}}$ and $D_{\mathrm{Li}}^{\mathrm{s}}$ of $4.0 \times 10^{-21} \mathrm{~m}^{2} / \mathrm{s}$ and $8.0 \times 10^{-21} \mathrm{~m}^{2} / \mathrm{s}$, respectively, for CJ-6 and $2.0 \times 10^{-21} \mathrm{~m}^{2} / \mathrm{s}$ and $4.0 \times 10^{-21} \mathrm{~m}^{2} / \mathrm{s}$, respectively, for SON68. A value for $\alpha$ of 1 was also used for both glasses. A ratio of 2 for $D^{\mathrm{s}} / D^{\mathrm{b}}$ was obtained for both glasses; therefore, to limit the number of model parameters, this ratio was used in all subsequent fits. The diffusion coefficients used to fit the SON68 data are lower than those used for CJ-6, which is a similar trend to what was observed in the isolated diffusion case. 
The data for the outward-diffusing ${ }^{7} \mathrm{Li}$ is given in Figure $\mathbf{5 c}$ and $\mathrm{d}$ for CJ-6 and SON68, respectively. The main finding is that the same set of parameters yields good agreement with both the ${ }^{6} \mathrm{Li}$ and ${ }^{7} \mathrm{Li}$ experimental depth profiles. It should be noted that the calculated profile goes through zero at the surface (i.e. all ${ }^{7} \mathrm{Li}$ at the solution/glass interface is released into solution) while the experimental profile does not. We have examined this phenomenon by forcing the intensity to zero at the solution/glass interface but this does not seem to improve the quality of the fit. However, as already mentioned, the glass may contain a non-exchangeable alkali fraction that is not participating in ion exchange that is the cause of the deviation between experimental and modeling results near the surface.

The experimental and calculated depth profiles of $\mathrm{Na}$ are given in Figure 6. In order to achieve the fits, $D_{\mathrm{Na}}^{\mathrm{b}}$ and $D_{\mathrm{Na}}^{\mathrm{s}}$ were set to $2.0 \times 10^{-20} \mathrm{~m}^{2} / \mathrm{s}$ and $4.0 \times 10^{-20} \mathrm{~m}^{2} / \mathrm{s}$, respectively, for CJ-6 and $1.0 \times 10^{-20} \mathrm{~m}^{2} / \mathrm{s}$ and $2.0 \times 10^{-20} \mathrm{~m}^{2} / \mathrm{s}$, respectively, for SON68. Therefore, it was necessary to use diffusion coefficients that were 5 times faster than the diffusion coefficients used to model ${ }^{6} \mathrm{Li}-{ }^{7} \mathrm{Li}$ diffusion for both glasses. This was indeed an unexpected result and further experiments are being performed to understand this phenomenon including performing a similar experiment with a Na-free glass. In addition, a structural factor was not used for modeling Na diffusion, as noted in section 2.3.2. This can be explained through the physical meaning of the structural factor which would only be necessary when a larger cation is replaced by a smaller one and by the faster diffusing ion affecting the slower diffusing ion from stress field gradients set up by slight differences in diffusivities.

\section{Discussion}

In glass corrosion studies, the vitreous material is commonly subjected to alteration in an aqueous environment at various temperatures, $\mathrm{pH}$, and solutions of various chemical compositions. As already stated in the Introduction, it is generally agreed upon that, at the onset of the alteration of the glass, two alteration processes occur simultaneously: ion exchange of water for alkali ions in the glass (Doremus, 1975; Rébiscoul et al., 2012; Rébiscoul et al., 2007), and the hydrolysis of the network, involving the dissociation of metal-oxygen covalent bonds (metal $=\mathrm{Si}, \mathrm{Al}, \mathrm{Zr} \ldots$ ). Hydrated surface layers can form 
both when sparingly soluble glass components accumulate and condense at the glass-water interface as well as when $\mathrm{H}^{+}, \mathrm{H}_{2} \mathrm{O}$, or $\mathrm{H}_{3} \mathrm{O}^{+}$diffuses into the undissolved glass network. In the present set of experiments, we have eliminated the hydrolysis reaction by using an inert organic solution. This has allowed us to focus on the low temperature diffusion of alkali ions in the absence of alteration layers that eliminates the presence of a moving boundary and limits the effect of chemical reactions on alkali diffusion. Most importantly, the source and nature of the diffusing species involved in ion exchange remains a matter of debate. The species could be hydronium from solution or the result of a dissociation reaction (Equation 1) (McGrail et al., 2001). Either way, the introduction of the diffusing species into the solid state would be a mechanism separate to interdiffusion within the solid. The present work was designed to eliminate the question of source entirely.

From the study, we have shown that there is a continuous flux of ${ }^{6} \mathrm{Li}^{+}$into the glass and of ${ }^{7} \mathrm{Li}^{+}$and $\mathrm{Na}^{+}$out of the glass. This diffusion-controlled ion exchange results in ${ }^{6} \mathrm{Li}$ penetration depths that increase with time. The ${ }^{6} \mathrm{Li}$ movement from the liquid phase into the glass was correlated with a depletion of ${ }^{7} \mathrm{Li}$ and $\mathrm{Na}$. The Li-for-Li exchanged to similar depths thus allowing good fits of the shapes and depths of the two isotopes. On the other hand, it seems that sodium exchanged slightly faster than Li, leading to a slightly deeper diffusion depth. The reason for this remains unclear at present, although more experiments and molecular simulations are underway to investigate this phenomenon. One would expect the smaller Li atom to more easily diffuse through the compact vitreous matrix than the larger $\mathrm{Na}$ atom. However, the $\mathrm{Li}$ ion possesses a larger charge field strength than $\mathrm{Na}$ ion and this may result in a slower diffusion through the glass. Additionally, the exchange of ions with different sizes may lead to local stresses within the glass that could facilitate (tensile) or hinder (compressive) further interdiffusion. Another issue may be the structural role that $\mathrm{Li}$ and $\mathrm{Na}$ play in the glass network. The alkalis may act as charge compensators on the tetrahedral borate or aluminate sites or create non-bridging oxygen (NBO) sites in the network. If the partitioning between the sites is not equal, one could expect different behaviors of the two ions. For 
instance, if Na preferentially partitions to NBO sites one could expect that the release of this ion from this site is faster than the release of the ion from the tetrahedral sites.

All diffusion profiles show a sigmoidal behavior that leads to modeling with the interdiffusion model. It should be noted that in the absence of $\mathrm{Na}$, the $\mathrm{Li}$ profile should follow the isolated case, i.e. the diffusion coefficient of the inward- and outward-diffusing species is equal. Mathematically, this can be explained by $\mathrm{C}_{\mathrm{Na}}$ in Equation 5 being equal to zero and thus there is will be no change in the diffusion coefficient with increasing depth into the glass. We may, however, expect some sort of sigmoidal shape due to Li fractionation that has previously been observed in minerals and glasses (Richter et al., 2014; Verney-Carron et al., 2011). Experiments investigating Li diffusion in Na-free glasses are currently being conducted to confirm this hypothesis.

The models universally showed that the diffusion coefficients for CJ-6 were 2 to 2.5 times larger than those for SON68. One possible explanation is that the simpler structure of the 6-oxide CJ-6 glass facilitates movement. This can be compared to the SON68 glass that has a higher molar density based on the number of metal oxides in the glass. This may create a more tortuous path for the outward diffusing alkali ions and thus lowering the diffusion coefficient of the inward and outward diffusing species. Another difference between the fits of the two glasses is the overall better fits for the more simple CJ-6 glass. Though the exact reason for the better fits with the CJ-6 glass compared to the 26-oxide SON68 glass are unknown, it can be expected that the added complexity of the glass leads to a wide variety of local structural features that are likely not explained by our simple interdiffusion model (e.g. iron, cesium, molybdenum).

\subsection{Implications for Nuclear Waste Glass Disposal}

Previous studies on the long-term corrosion of nuclear waste glass often dealt with diffusion as the process that controls the long-term residual dissolution rate of the glass. The inward diffusing species is most often assumed to be water. A diffusion profile of an inward diffusing water species is anti-correlated with an outward-diffusing alkali species, most often Na. Studies that have considered this process, for 
both glasses and minerals, often model the results by assuming a moving boundary condition. This means that the diffusion of the species occurs at the same rate as a disappearing boundary, mainly the dissolution of the glass. This creates a condition where the depth profile remains constant with time. From this condition the reaction is said to be in steady-state. This creates a case where the rate of dissolution of the glass is diffusion controlled but continues at a constant rate. For the experiments given in this study, we have eliminated the condition of a moving boundary. It is seen that the depth of the ${ }^{6} \mathrm{Li}$ penetrating from solution into the glass increases with time and, because the rate of this penetration is diffusion controlled, the rate of penetration is decreasing asymptotically to zero. Because the rate of diffusion is assumed to be constant this may be an oversimplification and a conservative view of the diffusion process.

Another issue is the value of the diffusion coefficients that were used, which are on the order of $10^{-20}$ $10^{-21} \mathrm{~m}^{2} / \mathrm{s}$. The diffusion coefficients are on the same order of magnitude as those measured by Rébiscoul et al. (2007) at $50^{\circ} \mathrm{C}$ who gave short term hydrogen diffusion coefficient values of $(5.1 \pm 0.4) \times 10^{-}$ ${ }^{20} \mathrm{~m}^{2} / \mathrm{s}$ at $\mathrm{pH} 3.2$ and $(6.5 \pm 0.7) \times 10^{-21} \mathrm{~m}^{2} / \mathrm{s}$ at $\mathrm{pH} 5.7$ for SON68. On the other hand, when an alteration layer is present as a result of glass corrosion in aqueous conditions, as observed for $\mathrm{H} / \mathrm{Li}$ exchange in SON68 after 25.75 years of aqueous alteration at $90{ }^{\circ} \mathrm{C}$, diffusion coefficients of $1.5 \times 10^{-22} \mathrm{~m}^{2} / \mathrm{s}$ and $6.8 \times 10^{-23} \mathrm{~m}^{2} / \mathrm{s}$ for $\mathrm{Li}$ and $\mathrm{H}$, respectively, gave the best profile fits (Gin et al., 2013b).

This would suggest that the diffusion of species is slowed once an alteration layer is formed on the glass surface. It still remains unclear if the exchange of elements through this layer is the mechanism controlling the long-term glass corrosion rate. More studies should be performed to investigate the physical properties of the layer. With better understanding of the layer more reliable modeling of the long-term corrosion rate, especially when the system is saturated with respect to $\mathrm{Si}$, can be achieved.

\section{Summary}

Here we have examined the diffusion of alkali ions at $90{ }^{\circ} \mathrm{C}$ in the absence of the hydrolysis reaction for two glasses relevant to the studies of nuclear waste glass corrosion, SON68 and CJ-6. The results show that $\mathrm{Li}$ from the non-aqueous solution replaces $\mathrm{Li}$ and $\mathrm{Na}$ from the glass through a diffusion 
controlled process. Modelling of the alkali diffusion profiles demonstrated that the diffusion of the inward-diffusing species and the outward-diffusing species changes as a function of depth. This diffusion coefficient, which changes as a function of the sodium concentration it the glass, can be attributed to different diffusion coefficients of the inward- and outward-diffusing species as well as to structural changes that occur during the exchange process. We were unable to simultaneously model the behavior of $\mathrm{Li}$ and $\mathrm{Na}$, i.e. the profiles were solved independently. Alkali diffusion coefficients for SON68, the 26oxide simulant glass, were calculated to be from $2.0-4.0 \times 10^{-21} \mathrm{~m}^{2} / \mathrm{s}$ for $\mathrm{Li}$ and $1.0-2.0 \times 10^{-20} \mathrm{~m}^{2} / \mathrm{s}$ for Na. For CJ-6, the 6-oxide glass, the diffusion coefficient were calculated to be from $4.0-8.0 \times 10^{-21} \mathrm{~m}^{2} / \mathrm{s}$ for $\mathrm{Li}$ and $2.0-4.0 \times 10^{-20} \mathrm{~m}^{2} / \mathrm{s}$ for Na. From these values we can assume that the alteration layer formed during glass corrosion can act as a layer that controls a diffusion reaction. More experiments are being performed to investigate diffusion in the presence and absence of alteration layers to be able to better predict the long-term performance of nuclear waste glass in a geological repository.

\section{Acknowledgements}

These studies were supported by the U.S. Department of Energy (DOE) through the Office of Environmental Management. Pacific Northwest National Laboratory is operated for the DOE by Battelle Memorial Institute under Contract DE-AC06-76RLO 1830. We would like to thank Peter Rieke of PNNL for his help in improving the manuscript and Jesse Lang also of PNNL for help in sample preparation.

The research described in this paper was performed in part in the Environmental Molecular Sciences Laboratory, a national scientific user facility sponsored by the U.S. Department of Energy's Office of Biological and Environmental Research and located at Pacific Northwest National Laboratory in Richland, WA.

\section{References}

Advocat, T., Jollivet, P., Crovisier, J.L. and del Nero, M. (2001) Long-term alteration mechanisms in water for SON68 radioactive borosilicate glass. Journal of Nuclear Materials 298, 55-62.

Cailleteau, C., Angeli, F., Devreux, F., Gin, S., Jestin, J., Jollivet, P. and Spalla, O. (2008) Insight into silicate-glass corrosion mechanisms. Nature Materials 7, 978-983. 
Chave, T., Frugier, P., Ayral, A. and Gin, S. (2007) Solid state diffusion during nuclear glass residual alteration in solution. Journal of Nuclear Materials 362, 466-473.

Chomat, L., Bouyer, F., Gin, S. and Roux, S. (2012) Effect of leaching-driven flow on the alteration kinetics of an ideal crack in SON68 glass. Journal of Nuclear Materials 426, 160-172.

Crank, J. (1975) The Mathematics of Diffusion, Second Edition ed. Clarendon Press, Oxford.

Doremus, R.H. (1975) Interdiffusion of Hydrogen and Alkali Ions in a Glass Surface. Journal of NonCrystalline Solids 19, 137.

Ebert, W.L., Fortner, J.A., Crawford, C.L. and Marra, J.C. (2012) Stage 3 Dissolution Tests with AFCI Glass. U.S. Department of Energy, Washington, D.C.

El-Shamy, T.M. and Pantano, C.G. (1977) Decomposition of silicate glasses in alkaline solutions. Nature 266, 704-706.

Ellison, A. and Cornejo, I.A. (2010) Glass Substrates for Liquid Crystal Displays. International Journal of Applied Glass Science 1, 87-103.

Ferrand, K., Abdelouas, A. and Grambow, B. (2006) Water diffusion in the simulated French nuclear waste glass SON 68 contacting silica rich solutions: Experimental and modeling. Journal of Nuclear Materials 355, 54-67.

Fournier, M., Gin, S. and Frugier, P. (2014) Resumption of nuclear glass alteration: State of the art. Journal of Nuclear Materials 448, 348-363.

Frugier, P., Gin, S., Minet, Y., Chave, T., Bonin, B., Godon, N., Lartigue, J.E., Jollivet, P., Ayral, A., De Windt, L. and Santarini, G. (2008) SON68 nuclear glass dissolution kinetics: Current state of knowledge and basis of the new GRAAL model. Journal of Nuclear Materials 380, 8-21.

Gin, S., Abdelouas, A., Criscenti, L.J., Ebert, W.L., Ferrand, K., Geisler, T., Harrison, M.T., Inagaki, Y., Mitsui, S., Mueller, K.T., Marra, J.C., Pantano, C.G., Pierce, E.M., Ryan, J.V., Schofield, J.M., Steefel, C.I. and Vienna, J.D. (2013a) An international initiative on long-term behavior of high-level nuclear waste glass. Materials Today 16, 243-248.

Gin, S., Beaudoux, X., Angéli, F., Jégou, C. and Godon, N. (2012) Effect of composition on the shortterm and long-term dissolution rates of ten borosilicate glasses of increasing complexity from 3 to 30 oxides. Journal of Non-Crystalline Solids 358, 2559-2570.

Gin, S., Ryan, J.V., Schreiber, D.K., Neeway, J.J. and Cabié, M. (2013b) Contribution of atom-probe tomography to a better understanding of glass alteration mechanisms: application to a nuclear glass specimen altered 25 years in a granitic environment. Chemical Geology 349-350, 99-109.

Gong, W.L., Wang, L.M., Ewing, R.C., Vernaz, E., Bates, J.K. and Ebert, W.L. (1998) Analytical electron microscopy study of surface layers formed on the French SON68 nuclear waste glass during vapor hydration at $200{ }^{\circ} \mathrm{C}$. Journal of Nuclear Materials 254, 249-265.

Grambow, B. and Müller, R. (2001) First-order dissolution rate law and the role of surface layers in glass performance assessment. Journal of Nuclear Materials 298, 112-124.

Guittonneau, C., Gin, S., Godon, N., Mestre, J.P., Dugne, O. and Allegri, P. (2011) A 25-year laboratory experiment on French SON68 nuclear glass leached in a granitic environment - First investigations. Journal of Nuclear Materials 408, 73-89.

Guo, X., Pivovarov, A.L., Smedskjaer, M.M., Potuzak, M. and Mauro, J.C. (2014) Non-conservation of the total alkali concentration in ion-exchanged glass. Journal of Non-Crystalline Solids 387, 71-75.

Hellmann, R. (1997) The albite-water system .4. Diffusion modeling of leached and hydrogen-enriched layers. Geochimica et Cosmochimica Acta 61, 1595-1611.

Icenhower, J.P., McGrail, B.P. and Luttge, A. (2002) Origins of deviations from transition-state theory: Effects of ion-exchange kinetics in glass. Geochimica Et Cosmochimica Acta 66, A351.

Jantzen, C.M., Brown, K.G. and Pickett, J.B. (2010) Durable glass for thousands of years. International Journal of Applied Glass Science 1, 38-62.

Jégou, C. (1998) Mise en évidence expérimentale des mécanismes limitant l'altération du verre R7T7 en milieu aqueux. Critique et proposition d'évolution du formalisme cinétique. Université de Montpellier II. 
Jiřička, A., Vienna, J.D., Hrma, P. and Strachan, D.M. (2001) The effect of experimental conditions and evaluation techniques on the alteration of low activity glasses by vapor hydration. Journal of NonCrystalline Solids 292, 25-43.

Jollivet, P., Angeli, F., Cailleteau, C., Devreux, F., Frugier, P. and Gin, S. (2008) Investigation of gel porosity clogging during glass leaching. Journal of Non-Crystalline Solids 354, 4952-4958.

Jollivet, P., Frugier, P., Parisot, G., Mestre, J.P., Brackx, E., Gin, S. and Schumacher, S. (2012) Effect of clayey groundwater on the dissolution rate of the simulated nuclear waste glass SON68. Journal of Nuclear Materials 420, 508-518.

Kato, Y., Yamazaki, H. and Tomozawa, M. (2001) Detection of Phase Separation by FTIR in a LiquidCrystal-Display Substrate Aluminoborosilicate Glass. Journal of the American Ceramic Society 84, 2111-2116.

Lanford, W.A. (1979) Hydration of Soda-Lime Glass. J. Noncrystalline Solids 33, 249-266.

McGrail, B.P., Bacon, D.H., Meyer, P.D., Ojovan, M.I., Strachan, D.M., Ojovan, N.V. and Startceva, I.V. (2003) New developments in field studies of low activity waste glass corrosion and contamination transport. Materials Research Society Symposium Proceedings 757, 83-95.

McGrail, B.P., Icenhower, J.P., Shuh, D.K., Liu, P., Darab, J.G., Baer, D.R., Thevuthasen, S., Shutthanandan, V., Engelhard, M.H., Booth, C.H. and Nachimuthu, P. (2001) The structure of $\mathrm{Na}_{2} \mathrm{O}-$ $\mathrm{Al}_{2} \mathrm{O}_{3}-\mathrm{SiO}_{2}$ glass: impact on sodium ion exchange in $\mathrm{H}_{2} \mathrm{O}$ and $\mathrm{D}_{2} \mathrm{O}$. Journal of Non-Crystalline Solids 296, 10-26.

Neeway, J., Abdelouas, A., Grambow, B. and Schumacher, S. (2011) Dissolution mechanism of the SON68 reference nuclear waste glass: New data in dynamic system in silica saturation conditions. Journal of Nuclear Materials 415, 31-37.

Neeway, J., Abdelouas, A., Grambow, B., Schumacher, S., Martin, C., Kogawa, M., Utsunomiya, S., Gin, S. and Frugier, P. (2012) Vapor hydration of SON68 glass from $90^{\circ} \mathrm{C}$ to $200^{\circ} \mathrm{C}$ : A kinetic study and corrosion products investigation. Journal of Non-Crystalline Solids 358, 2894-2905.

Ojovan, M.I., Pankov, A. and Lee, W.E. (2006) The ion exchange phase in corrosion of nuclear waste glasses. Journal of Nuclear Materials 358, 57-68.

Pierce, E.M., McGrail, B.P., Bagaasen, L.M., Rodriguez, E.A., Wellman, D.M., Geiszler, K.N., Baum, S.R., Reed, L.R., Crum, J.V. and Schaef, H.T. (2005) Laboratory Testing of Bulk Vitrified LowActivity Waste Forms to Support the 2005 Integrated Disposal Facility Performance Assessment. Pacific Northwest National Laboratory, Richland, WA.

Rébiscoul, D., Bruguier, F., Magnin, V. and Gin, S. (2012) Impact of soda-lime borosilicate glass composition on water penetration and water structure at the first time of alteration. Journal of NonCrystalline Solids 358, 2951-2960.

Rébiscoul, D., Rieutord, F., Né, F., Frugier, P., Cubitt, R. and Gin, S. (2007) Water penetration mechanisms in nuclear glasses by X-ray and neutron reflectometry. Journal of Non-Crystalline Solids $353,2221-2230$.

Ribet, S. and Gin, S. (2004) Role of neoformed phases on the mechanisms controlling the resumption of SON68 glass alteration in alkaline media. Journal of Nuclear Materials 324, 152-164.

Richter, F., Watson, B., Chaussidon, M., Mendybaev, R. and Ruscitto, D. (2014) Lithium isotope fractionation by diffusion in minerals. Part 1: Pyroxenes. Geochimica et Cosmochimica Acta 126, 352-370.

Smedskjaer, M.M., Zheng, Q., Mauro, J.C., Potuzak, M., Mørup, S. and Yue, Y. (2011) Sodium diffusion in boroaluminosilicate glasses. Journal of Non-Crystalline Solids 357, 3744-3750.

Strachan, D.M. and Neeway, J.J. (2014) Effects of alteration product precipitation on glass dissolution. Applied Geochemistry 45, 144-157.

Traynelis, V.J. and Hergenrother, W.L. (1964) Decomposition of Dimethyl Sulfoxide Aided by Ethylene Glycol, Acetamide, and Related Compounds1. The Journal of Organic Chemistry 29, 221-222.

Valle, N., Verney-Carron, A., Sterpenich, J., Libourel, G., Deloule, E. and Jollivet, P. (2010) Elemental and isotopic (Si-29 and O-18) tracing of glass alteration mechanisms. Geochimica et Cosmochimica Acta 74, 3412-3431. 
Van Iseghem, P., Aertsens, M., Gin, S., Deneele, D., Grambow, B., McGrail, B.P., Strachan, D. and Wicks, G.G. (2006) A Critical Evaluation of the Dissolution Mechanisms of High-level Waste Glasses in Conditions of Relevance for Geological Disposal (GLAMOR), European Commission,.

Varshneya, A.K. (1994) Fundamentals of Inorganic Glasses. Academic Press Inc., San Diego, CA, USA.

Varshneya, A.K. (2010) The physics of chemical strengthening of glass: Room for a new view. Journal of Non-Crystalline Solids 356, 2289-2294.

Vernaz, E.Y. and Dussossoy, J.L. (1992) Current state of knowledge of nuclear waste glass corrosion mechanisms: the case of R7T7 glass. Applied Geochemistry 1, 13-22.

Verney-Carron, A., Vigier, N. and Millot, R. (2011) Experimental determination of the role of diffusion on $\mathrm{Li}$ isotope fractionation during basaltic glass weathering. Geochimica et Cosmochimica Acta 75, 3452-3468.

Vienna, J.D. (2010) Nuclear Waste Vitrification in the United States: Recent Developments and Future Options. International Journal of Applied Glass Science 1, 309-321.

Wang, Z., Zhao, E., Liu, B., Wang, Y.-C., Zhang, H., Hong, M., Neeway, J., Le Guernic, S., Suntharampilai, T., Wang, F. and Zhu, Z. (2014) Argon Cluster: A Unique Ion Source for Precise Dual-beam Depth Profiling of Nuclear Waste Glass and Other Insulating Materials in ToF-SIMS. submitted to Analytical Chemistry.

Wu, X., Moskowitz, J.D., Mauro, J.C., Potuzak, M., Zheng, Q. and Dieckmann, R. (2012) Sodium tracer diffusion in sodium boroaluminosilicate glasses. Journal of Non-Crystalline Solids 358, 1430-1437. 
Table 1. Glass Composition in mass $\%$ and mol\% oxide. The minor elements in SON68 are given in Ribet (2004).

\begin{tabular}{l|rr|rr}
\hline Oxide & \multicolumn{1}{|l|}{ mass\% } & \multicolumn{1}{l}{ mol\% } \\
& \multicolumn{1}{l}{ SON68 } & CJ-6 & \multicolumn{1}{l}{ SON68 } & CJ-6 \\
\hline \hline $\mathrm{SiO}_{2}$ & $45.9 \%$ & $52.3 \%$ & $52.7 \%$ & $56.6 \%$ \\
$\mathrm{~B}_{2} \mathrm{O}_{3}$ & $14.1 \%$ & $16.2 \%$ & $14.0 \%$ & $15.1 \%$ \\
$\mathrm{Na}_{2} \mathrm{O}$ & $10.2 \%$ & $11.2 \%$ & $11.4 \%$ & $11.8 \%$ \\
$\mathrm{CaO}$ & $4.1 \%$ & $4.7 \%$ & $5.0 \%$ & $5.4 \%$ \\
$\mathrm{Li}_{2} \mathrm{O}$ & $2.0 \%$ & $2.3 \%$ & $4.6 \%$ & $5.0 \%$ \\
$\mathrm{Al}_{2} \mathrm{O}_{3}$ & $5.0 \%$ & $5.7 \%$ & $3.4 \%$ & $3.6 \%$ \\
$\mathrm{ZrO}_{2}$ & $2.8 \%$ & $3.1 \%$ & $1.5 \%$ & $1.6 \%$ \\
$\mathrm{Fe}_{2} \mathrm{O}_{3}$ & $3.0 \%$ & --- & $1.3 \%$ & --- \\
$\mathrm{Ce}_{2} \mathrm{O}_{3}$ & $1.0 \%$ & $4.6 \%$ & $0.2 \%$ & $0.9 \%$ \\
$\mathrm{Others}^{2}$ & $11.9 \%$ & --- & $5.9 \%$ & --- \\
\hline
\end{tabular}

${ }^{\text {a }}$ SON68 contains other minor elements 


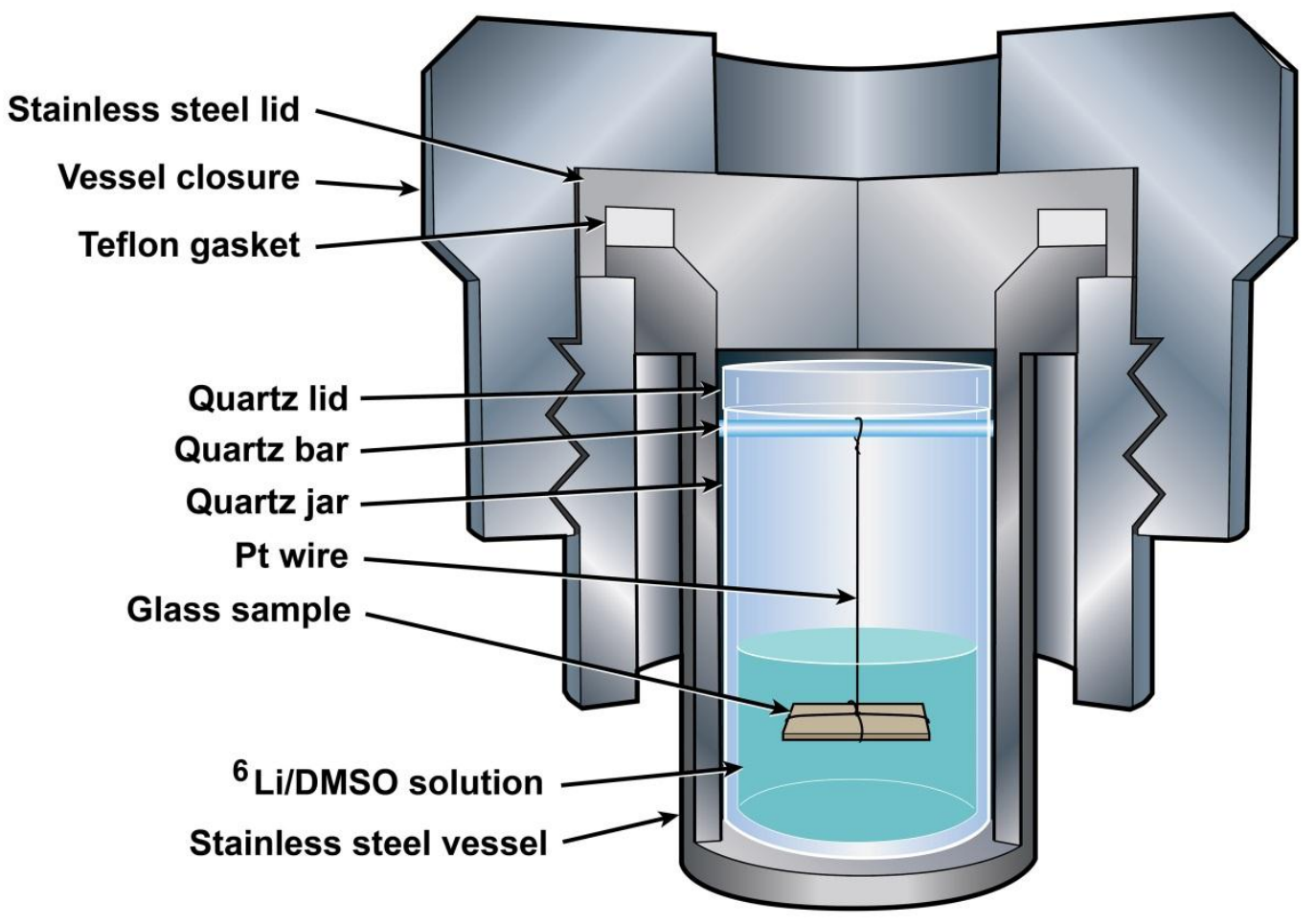

Figure 1. Schematic of the system used for conducting the ion exchange experiments. 


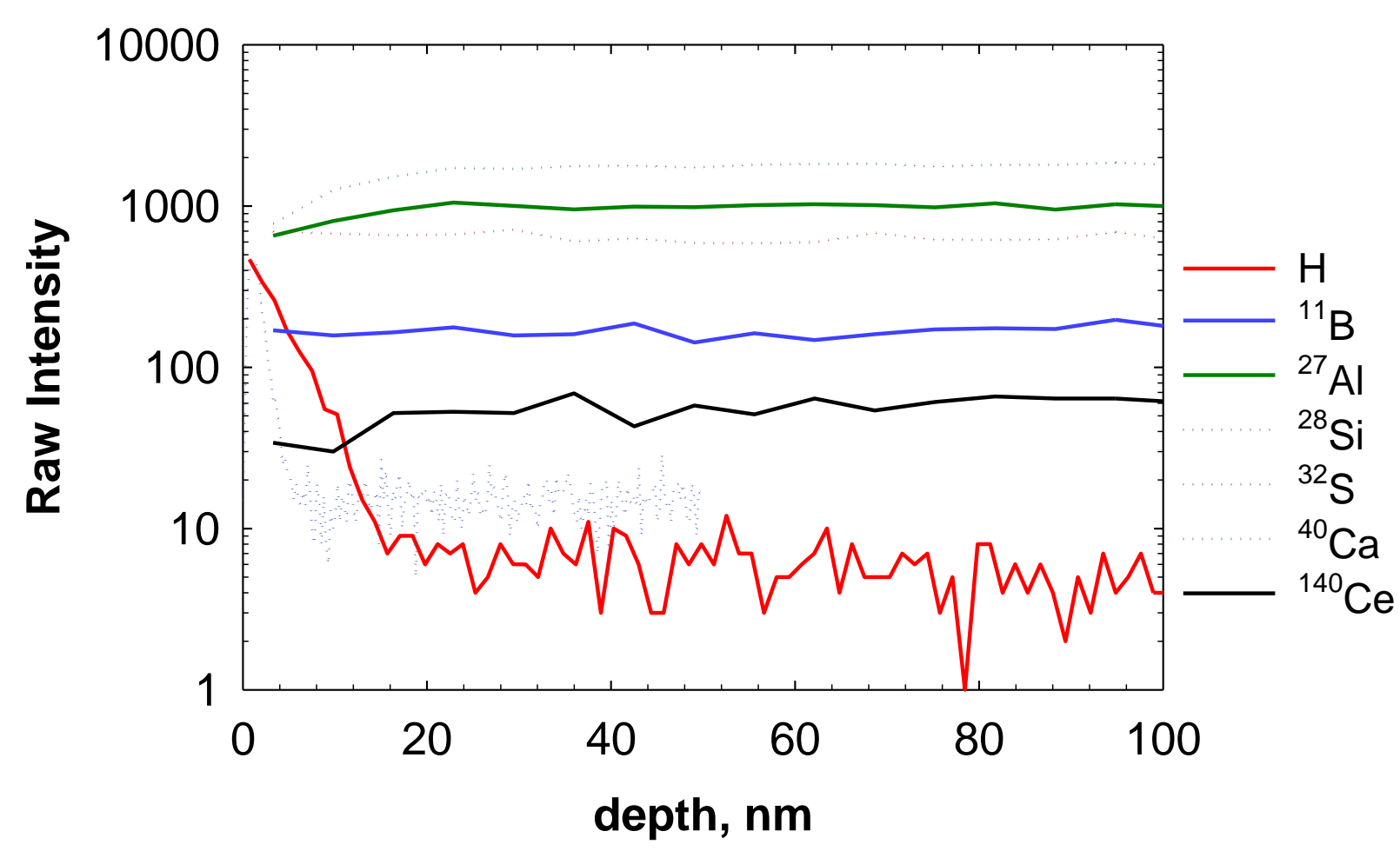

Figure 2. Depth profiles of major glass network elements of CJ-6 after 89 days of contact with the $\mathrm{Li} / \mathrm{DMSO}$ solution. The $\mathrm{H}$ intensity comes from measurement using an $\mathrm{O}_{2}{ }^{+}$sputter beam, the $\mathrm{S}$ intensity comes from measurements using a $\mathrm{Cs}^{+}$sputter beam, while the other elements were obtained from an $\mathrm{Ar}_{\mathrm{n}}{ }^{+}$ sputter beam. 

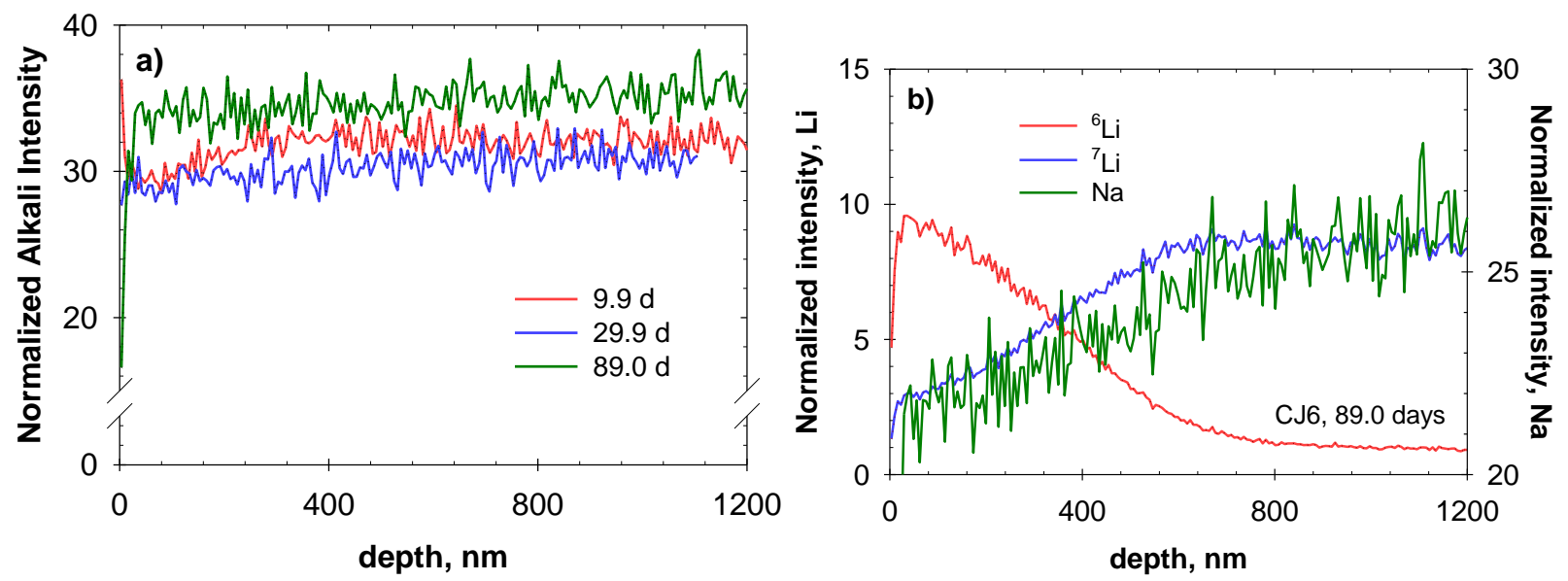

Figure 3. a) The total alkali intensity normalized to $\mathrm{Al}$ across the sample depth for the CJ-6 samples and b) the profiles of ${ }^{6} \mathrm{Li},{ }^{7} \mathrm{Li}$, and $\mathrm{Na}$ normalized to $\mathrm{Al}$ for the $\mathrm{CJ}-6$ sample after 89.0 days of contact with ${ }^{6} \mathrm{Li}$ in DMSO. The intensities have been normalized to the ${ }^{27} \mathrm{Al}$ intensity as a function of depth. 

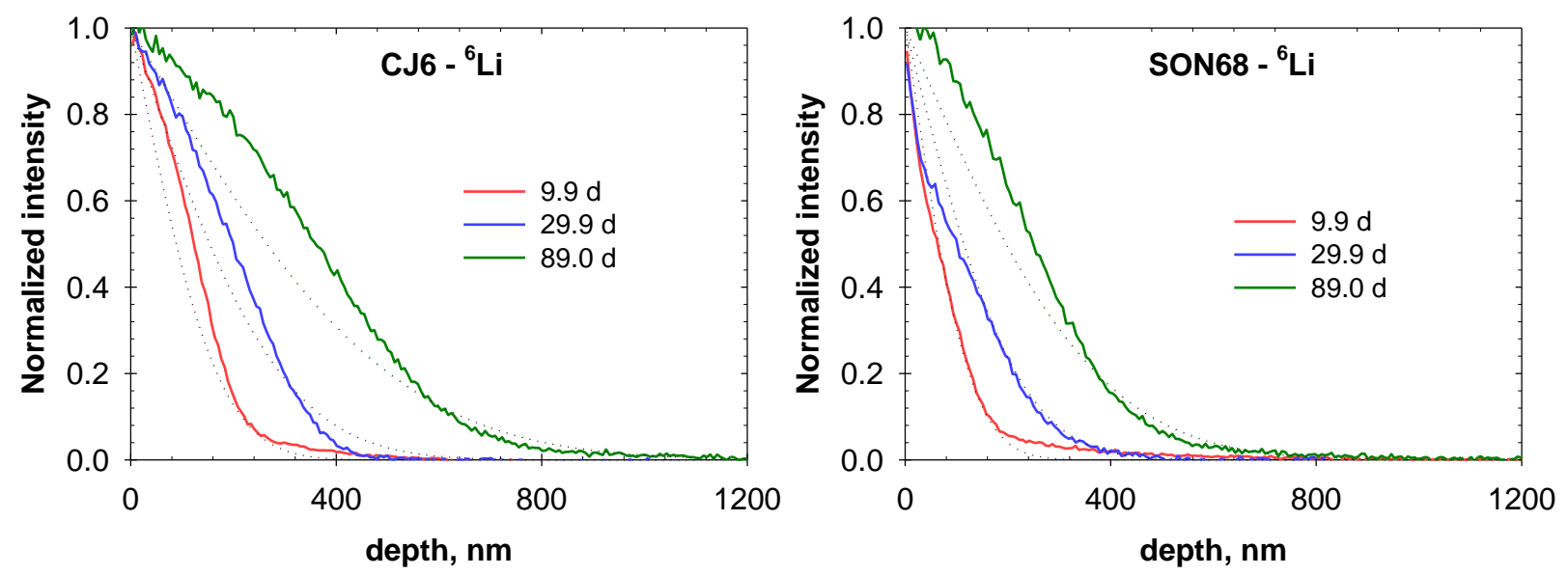

Figure 4. Experimental ${ }^{6} \mathrm{Li}$ depth profiles (solid lines) and calculated profiles (dashed lines) obtained with the isolated diffusion model for CJ-6 (left) and SON68 (right). Diffusion coefficients of $1.0 \times 10^{-20}$ $\mathrm{m}^{2} / \mathrm{s}$ and $5.5 \times 10^{-21} \mathrm{~m}^{2} / \mathrm{s}$ were used for CJ-6 and SON68, respectively. 

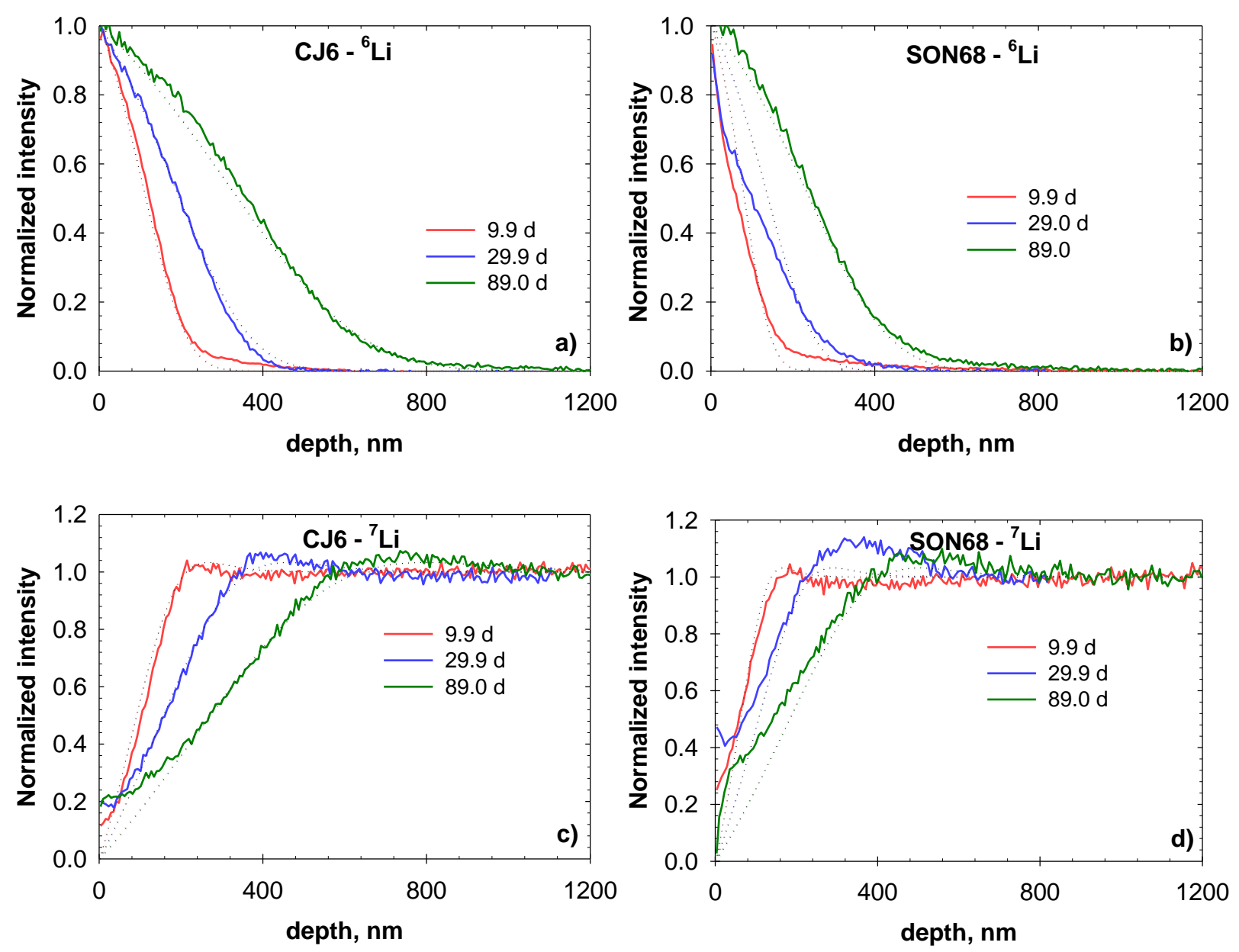

Figure 5. Experimental ${ }^{6} \mathrm{Li}$ and ${ }^{7} \mathrm{Li}$ depth profiles (solid lines) and calculated profiles (dashed lines) obtained with the interdiffusion model for CJ-6 (left) and SON68 (right). Model parameters are given in the text. 

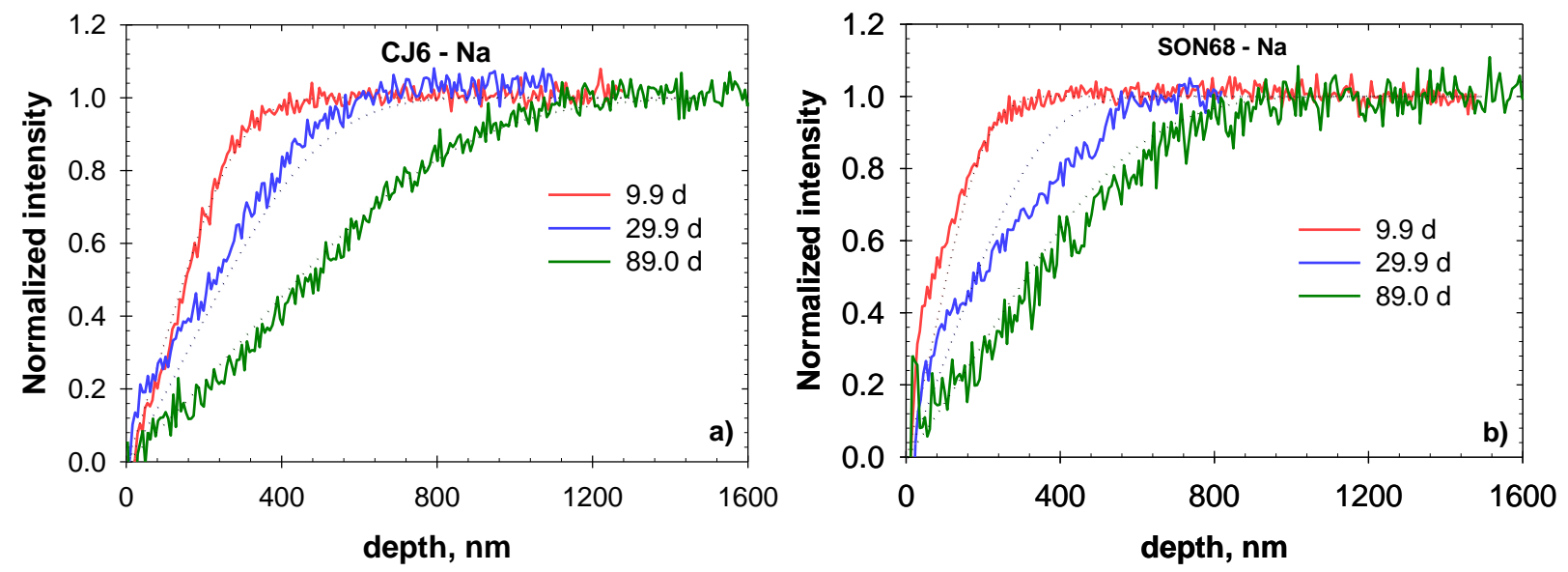

Figure 6. Experimental Na depth profiles (solid lines) and calculated profiles (dashed lines) obtained with the interdiffusion model for CJ-6 (left) and SON68 (right). Model parameters are given in the text. 